\title{
THE EXTENDED UTAUT MODEL AND LEARNING MANAGEMENT SYSTEM DURING COVID-19: EVIDENCE FROM PLS-SEM AND CONDITIONAL PROCESS MODELING
}

\author{
Rizwan Raheem AHMED ${ }^{1}$, Dalia ŠTREIMIKIENË ${ }^{2,3^{*}}$, Justas ŠTREIMIKIS ${ }^{4}$ \\ ${ }^{1}$ Faculty of Management Sciences, Indus University, Gulshan-17, Karachi-75300, Pakistan \\ ${ }^{2}$ Lithuanian Sports University, Sporto 6, LT-44221 Kaunas, Lithuania \\ ${ }^{3}$ Lithuanian Centre for Social Sciences, Institute of Economics and Rural Development, \\ A. Vivulskio g. 4A-13, LT-03220 Vilnius, Lithuania \\ ${ }^{4}$ Faculty of Management and Finances, University of Economics and Human Science in Warsaw, \\ Okopowa 59, 01-043 Warsaw, Poland
}

Received 17 March 2021; accepted 28 June 2021; first published online 30 November 2021

\begin{abstract}
The undertaken research investigates the extended unified theory of acceptance and use of technology (UTAUT) model from the perspective of online education in the deadliest period of COVID-19. This research investigates the extended dimensions, for instance, mobile self-efficacy and perceived enjoyment besides traditional elements of the UTAUT model with the relationship of behavioural intention and user behaviour of LMS. Since the COVID-19 led to social isolation (SIS), thus, this study has incorporated SIS as mediating factor and fear of COVID-19 (FOC) as the moderating factor for the considered extended model of UTAUT. The data of 1875 respondents was collected from five different Asian countries. For the data analysis, this study employed structural equation modeling through PLS-SEM and condition process modeling. This research demonstrates that the extended dimensions such as mobile self-efficacy, besides the traditional elements of the UTAUT model, exerted a cogent impact on behavioural intention except for the perceived enjoyment. Similarly, the behavioural intention demonstrated a substantial effect on the user behaviour of LMS. Additionally, social isolation as a mediating factor and FOC has a significant effect between dimensions of extended UTAUT model and behavioural intention of LMS. The outcomes of this research demonstrate significant theoretical and practical implications during the COVID-19 pandemic.
\end{abstract}

Keywords: learning management system (LMS), higher education, extended unified theory of acceptance and use of technology (UTAUT) model, fear of COVID-19, social isolation, PLS-SEM.

JEL Classification: C12, C44, I21.

\footnotetext{
${ }^{\star}$ Corresponding author. E-mail: dalia.streimikiene@knf.vu.lt
} 


\section{Introduction}

The COVID-19 phenomenon surfaced from Wuhan, China, in 2019, and very soon, it was spread throughout the world due to an intense contagious rate, and it was declared a pandemic. According to Ain et al. (2016), the mortality rate was relatively high. Thus, people became terrified; as Lin (2020) suggested, individuals were worried because of the highly infectious nature of COVID-19. Therefore, Ahmed et al. (2020) demonstrated that governments worldwide had disseminated public guidelines, including self-quarantine, isolation, and social distancing, with exceptional psychological and economic effects. Effects of fear of COVID-19 (FOC) are irrepressible and irresistible for businesses of the planet. Subsequently, around 130 nations have bunged traditional classroom education, almost 1.5 billion students were affected due to COVID-19. Most countries have shifted their education system to elearning and online mode (Raza et al., 2021). Social distancing was the only precaution to prevent the Coronavirus. Thus, the world has closed schools and universities, and the education system has shifted to E-learning mode. Artificial intelligence and other modern learning modes have changed the traditional education system (Xian, 2019). The E-learning mode of education consisted of technology-based learning through learning portals, thousands of free websites, mobile apps, video conferencing, online interfaces, and YouTube. Therefore, during the COVID-19 pandemic, the education system shifted to E-learning, making it feasible to continue learning procedure throughout the lockdown universally (Kufi et al., 2020; Ahmed et al., 2020). The E-learning system is signified as "the learning management system" (LMS). The web-based LMS technology was established to progress a study procedure via its appropriate application, preparation, execution, and assessment in higher education institutes (Shahzad et al., 2021).

According to Raza et al. (2021) and Ain et al. (2016), the LMS is the learning procedure that facilitates and helps online because it delivers educational substance exclusive of restraint for time and place, allowing teacher and student to network through the Internet and enables the distribution, of course, associated resources and information (Shahzad et al., 2021). The LMS reminds us, expertise in technology for the learning process is the requirement of time during the COVID-19 pandemic. There are numerous LMS examples used in higher education institutions, for instance, Desire2Learn, Moodle, Blackboard, and WebCT (Iqbal, 2011). According to prior researches, for instance, Shahzad et al. (2021), and Raza et al. (2021), the reception of earning management system (LMS) among university students differs from country-to-country, as the registration of students belongs to the universities of Middle East was low. However, the E-learning system registration is very high in western countries during COVID-19 (Raza et al., 2021). Thus, the undertaken research evaluates antecedents, which affect LMS reception during the pandemic of COVID-19 in Asian countries. The traditional UTAUT model with additional two dimensions, for instance, mobile self-efficacy and perceived enjoyment, is employed. Moreover, this study also checked the impact of social isolation during COVID-19 in an association of independent factors \& behavioral intention and use behaviour of learning management system (LMS) in university students.

The traditional UTAUT model was employed and empirically verified for foreseeing practices and acceptance of crafting technology IT associated evaluations in several areas, for 
instance, ERP software (Raza et al., 2021). Similarly, Khalilzadeh et al. (2017) have demonstrated communication technologies, whiteboards (Šumak \& Šorgo, 2016), and mobile health (Hoque \& Sorwar, 2017). The UTAUT model offers a framework that elaborates acceptance of intermediate systems (ISs) and information technology and explains the actual usage of systems and technologies. The proficiency in assimilating TAMs and UTAUTs model provides the extensive examination of technology acceptance and its use (Venkatesh et al., 2003). Thus, the undertaken study employed the conceptual framework of the extended model of UTAUT to examine the technology stimuli, which are associated elements of LMS acceptance. However, the actual UTAUT model has been extensively employed, but uncertainties exist over its proficiency to elucidate individual technology adoption. Therefore, the previous researchers have extended or modified the actual UTAUT model and incorporated several external factors to enhance the effectiveness of this model (Khalilzadeh et al., 2017).

Therefore, the undertaken research has an extensive UTAUT model that integrates mobile self-efficacy and perceived enjoyment as independent factors. Additionally, this study incorporated social isolation as a mediator and fear of the COVID-19 pandemic as a moderating variable (Almaiah et al., 2020). Thus, this extended model evaluates the association between independent factors \& behavioral intention and use behavior of learning management system (LMS) in university students of Asian countries during the coronavirus phenomenon. Hence, this research examines the six dimensions of the extended UTAUT postulates and evaluates the connection between independent variables, and BI of students, \& actual use behavior of LMS. Similarly, this research also evaluates the impact of social isolation as a mediating variable and fear of COVID-19 playing as a moderating factor in a relationship of dimensions of the extended UTAUT model and behavioral intention and use behavior of LMS. This research's outcomes have important theoretical and practical implications for the policymakers, higher education institutions, parents, and other stakeholders to improve LMS and E-learning technologies for quality education.

The remainder of paper comprised of as Section 1 consisted on conjectural framework \& hypotheses development - Section 2 contained on materials \& methods, and Section 3 composed on findings \& data analyses. However, Section 4 consisted on discussions and last Section contained on conclusions.

\section{Conjectural framework and hypotheses formulation}

\subsection{The UTAUT model as a theoretical underpinning}

Previous literature, for instance, Venkatesh et al. (2003), have studied the information technology acceptance model and modified numerous new dimensions through their empirical findings. They constructed eight modified dimensions behavioral intention model vis-à-vis traditional IT models. Rendering to Davis et al. (1989), the conventional postulates include TRA. However, Davis et al. (1989) and Davis (1989) presented the TAM model. Similarly, Taylor and Todd (1995) derived the TPB model, and in the same vein, Thompson et al. (1991) offered the MPCU model. Similarly, Taylor and Todd (1995) combined two models: the TAM-TPB models. However, Vallerand (1997) presented the MM model, and Rogers 
(2003) derived the IDT model. Keeping given these models, some researchers have offered the UTAUT model in which they modified previous models and derived this new model for the users of technology acceptance (Venkatesh et al., 2003). They have integrated preceding models and derived the UTAUT model that explains the $70 \%$ variation of behavioral intention. Previous literature findings demonstrated the efficiency and effectiveness of the UTAUT model for any platform of technology adoption. The standard UTAUT model comprises six dimensions, for instance, effort expectancy (EE), performance expectancy (PE), facilitating conditions (FC), social influence (SI), behavioral intention (BI), and usage behavior of the IT system (Alhramelah \& Al-Shahrani, 2020). The undertaken research employed an extended UTAUT model to examine the learning management system's efficiency for the higher education students during COVID-19. However, there are some disadvantages of the UTAUT model, for instance, this model did not take into consideration the attitude, anxiety, and self-efficacy, which are the natural elements of intention, and attitude concerning employing technology does not have a direct impact on intentions (Raza et al., 2021).

\subsection{The performance expectancy - PE}

Venkatesh et al. (2003) has demonstrated the performance expectancy, as "it is the users' perception when using an E-learning system to enhance their performance." This dimension referred to the study performed from the perspective of online education. Rendering to Alhramelah and Al-Shahrani (2020), and Venkatesh et al. (2003), the dimension of performance expectancy is one of the most important regressors in the projection of students' behavioral intention for using the technology platform. According to Decman (2015), it is the students' trust regarding the efficacy of LMS for studying; similarly, Persada et al. (2019) have demonstrated that the performance expectancy is the level of students' understanding regarding the LMS and how it is beneficial to perform enhanced in their classrooms. However, Khechine et al. (2016) defined it in the context of efficiency, productivity, and effectiveness of the Elearning system, and they argued how much students benefit from adopting the LMS. Thus, researchers formulated the following hypothesis:

H1: The performance expectancy has a positive \& significant association with behavioral intention (BI).

\subsection{The effort expectancy - EE}

Similarly, Venkatesh et al. (2003) has described effort expectancy as "the perception of comfort in exercising the system. This construct signifies the comfort of using LMS among the students in the educational institutions while operating E-learning mode." According to Chen and Hwang (2019), and Raza et al. (2021), effort expectancy is one of the most vital elements of the UTAUT model. The effort expectancy element is also known as the intrinsic factor because of effort's volume of an individual observes to capitalize for using the technology that is low in usual because of the user-friendly flora of IT (Persada et al., 2019; Raza et al., 2021; Decman, 2015). Rendering to Venkatesh et al. (2003), the effort expectancy directly impacts behavioral intention in technology acceptance systems. The previous literature further 
demonstrated a consistent, affirmative, and cogent association between effort expectancy and behavioral intention prediction (Venkatesh et al., 2003). Thus, researchers have framed the subsequent hypothesis:

H2: The effort expectancy has a significant \& affirmative relationship with behavioral intention (BI).

\subsection{The social influence - SI}

Venkatesh et al. (2003) has demonstrated the social influence, as "it is the acumen of the significance, which others associate with the user for using the system." This construct signifies how opinions and perceptions of other people in the instantaneous social group influence the usage of online systems in higher education institutes. Mattila (2004) explained how this construct works in impacting an individual's prospect for using a technology interface. However, for examining the reception of LMS, social influence is the extent of the students' social sphere inducing their behavioral intention of LMS. According to Decman (2015), social networking sites are evolving, and information technology has sophisticated. Thus the emphasis of this construct has transferred from physical to virtual. Similarly, Raza et al. (2021), and Almisad and Alsalim (2020) have established a significant direct association of behavioral intention with the social influence of one concern the usage of technology in both compulsory and voluntary settings. Thus, researchers have framed the subsequent hypothesis:

H3: The social influence has a significant \& affirmative relationship with behavioral intention (BI).

\subsection{The facilitating conditions - FC}

Venkatesh et al. (2003) has demonstrated the facilitating conditions as "the accessibility of well-functioning technical inevitabilities to permit the users' handling of the system." The facilitating conditions range from procedural to human support and technical support to organizational support; in the perspective of the e-learning atmosphere, facilitating conditions emphasize the availability of technical structure to accept and use the LMS (Lai, 2020; Raza et al., 2021). According to Venkatesh et al. (2003), Decman (2015), the LMS includes technical support, training, and required infrastructure. Thus, in the original UTAUT model, FC's role is limited and insignificant due to the usage of different technology to influence an individual's behavioral intention. According to Ain et al. (2016), the lack of system support, limited technical assistance, and information hamper web-based technology's adoption level among university students. However, teachers' support, technical efficiency, and adequate information increase the FC, and therefore, facilitating conditions positively affect students' behavioral intention (Almisad \& Alsalim, 2020; Raza et al., 2021). Hence, researchers have framed the subsequent hypothesis:

H4: The facilitating conditions have a significant and affirmative relationship with behavioral intention (BI). 


\subsection{Mobile self-efficacy - MSE}

Rendering to Bandura (1986), self-efficacy is defined as “it is people's assessments of their effectiveness or ability to perform a specific task well; it is related not to the skills of an individual but rather to how he or she utilizes these skills." Thus, utilizing this perspective, self-efficacy is a person's trust that he/she retains the skills and aptitude to thrive while enchanting the tasks associated with m-technology (Ahmed et al., 2020; Raza et al., 2021). Therefore, according to Nikou and Economides (2017), mobile self-efficacy is described as "an individual's perceptions of his/her capability to use smartphone devices to achieve distinct jobs." The undertaken study has employed mobile self-efficacy as an external stimulus in online education that supports the students' knowledge of e-learning. Mobile self-efficacy has been demonstrated in several studies that showed an affirmative and cogent influence on behavioral intention (Ahmed et al., 2019). Therefore, researchers have framed the subsequent hypothesis:

H5: Mobile self-efficacy has an affirmative \& significant association with behavioral intention (BI).

\subsection{The perceived enjoyment - PRE}

Persada et al. (2019) defined the perceived enjoyment as "the extent to which the activity of using a specific system is perceived to be enjoyable in its own right, aside from any performance consequences resulting from system use." The perceived enjoyment is an essential intrinsic inspiration, which signifies the degree of fun enjoyment through information technology gadgets (Aliaño et al., 2019). Previous literature has confirmed the significant and positive impact of perceived enjoyment with a behavioral intention other than LMS acceptance. The perceived enjoyment is usually used as an outer TAM element (Law \& Fong, 2020). The perceived enjoyment is a vital construct, which positively impacts the PU, PEOU \& behavioral intention (BI) (Chen \& Hwang, 2019); however, the perceived enjoyment is being used as an external construct of the UTAUT model to investigate the behavioral intention (BI) of LMS. Thus, researchers have framed the following hypothesis:

H6: The perceived enjoyment has an affirmative \& significant association with behavioral intention (BI).

\subsection{User behavior of the LMS - UBL}

Most of the technology acceptance models certified that the concept of behavioral intention is the precursor of action. According to Raza et al. (2021) and Chen and Hwang (2019), in E-learning education, the user behavior of LMS is the student's actual action. Rendering to Fishbein and Ajzen (1975), user behavior is described, as "Behavioral intention measure will predict the performance of any voluntary act unless intent changes before the performance." Similarly, previous literature has established an affirmative and significant association between actual user behavior and behavioral intention by employing the UTAUT model (Aliaño et al., 2019; Raza et al., 2021; Khechine et al., 2016). Similarly, several previous 
studies confirmed the affirmative and cogent association amid behavioral intention and its actual usage of technology-based frameworks (Nikou \& Economides, 2017). Students' behavioral intention concerning the platform of E-learning acceptance demonstrates a cogent and affirmative connection with the user behavior of LMS (Alshurideh et al., 2020). Hence, researchers framed subsequent hypothesis:

H7: Behavioral intention has a significant \& affirmative influence on the user behavior of LMS.

\subsection{Social Isolation as a mediator}

The impact of Coronavirus is frightening and deadliest from China to the United States, and people are got into partial or complete isolation (Limaye et al., 2020; Ahmed et al., 2020). Because of the consistent information of social media or the mainstream media regarding the lethal magnitudes of COVID-19, people were more anxious and worried and refrained from going into public (Shahzad et al., 2021; Garrett, 2020). Thus, for the precautionary measures, people stayed at home in self-isolation worldwide (Iyer et al., 2020). Rendering to De Jong Gierveld et al. (2016), social isolation is described as "an individual's absence or the low number of significant connections with other people, thus making them socially isolated." Therefore, universities and other higher education institutions also faced similar consequences, and education went on online mode. According to Mertens et al. (2020), socially isolated students are more encouragingly connected to taking an online class through LMS. Thus, researchers have framed the following hypotheses:

H8A: Social isolation has a significant mediation in the association between PE \& LMS through BI.

H8B: Social isolation has a significant mediation in the association between EE \& LMS through BI.

H8C: Social isolation has a significant mediation in the association between SI \& LMS through BI.

H8D: Social isolation has a significant mediation in the association between FC \& LMS through BI.

H8E: Social isolation has a significant mediation in the association between MSE \& LMS through BI.

H8F: Social isolation has a significant mediation in the association between PRE \& LMS through BI.

H8G: Social isolation has a significant mediation in the association between BI \& user behavior of LMS.

\subsection{Fear of COVID-19 as a moderator}

According to Mertens et al. (2020), fear is described as "an adaptive feeling that activates energy in an individual to deal with an impending threat." The increase of the CODIV-19 pandemic has broader epidemiological and hazardous concerns that are not limited to the economic downturn and hampered universities and students (Ahmed et al., 2020). The 
delivery mode of education has been changed from traditional classroom to online teaching \& E-learning mode, and psychological effects will last for years (Raza et al., 2021). Extraordinary and unexpected circumstances like the coronavirus phenomenon enlarged a fear among people, and they indulge in severe psychological problems (Pakpour \& Griffiths, 2020). Thus, the students and teachers are afraid of physical contact due to the contiguous nature of COVID-19. Therefore, higher education institutions have shifted to E-learning medium. The most popular mode of E-learning is the learning management system (LMS) (Raza et al., 2021). Hence, university students accept the LMS to resume their learning development. Previous literature demonstrated that COVID-19 (FOC) fear has a moderating influence between exogenous and endogenous factors (Almaiah et al., 2020; Shahzad et al., 2021; Pakpour \& Griffiths, 2020; Raza et al., 2021; Ahmed et al., 2020). Thus, the following hypotheses are outlined:

H9A: FOC has a significant moderation in the association of PE and behavioral intention (BI).

H9B: FOC has a significant moderation in the association of EE and behavioral intention (BI).

H9C: FOC has a significant moderation in the association of SI and behavioral intention (BI).

H9D: FOC has a significant moderation in the association of FC and behavioral intention (BI).

H9E: FOC has a significant moderation in the association of MSE and behavioral intention (BI).

H9F: FOC has a significant moderation in the association of PRE and behavioral intention (BI).

H9G: FOC has a significant moderation in the association of BI and user behavior of LMS.

\section{Materials and methods}

\subsection{Scaling and research design}

This research employed an extended UTAUT model, adding two regressors: perceived enjoyment and mobile self-efficacy. Additionally, authors incorporated social isolation as a mediator and fear of COVID-19 as a moderator. The research design of this study is quantitative, and the nature of the study is cross-sectional. The researchers used modified items and constructs, which were taken from the previous literature. The measurement scales of social influence, performance expectancy, facilitating conditions, and effort expectancy was extracted from previous literature such as Decman (2015), Venkatesh et al. (2003), Khechine et al. (2016), and Ain et al. (2016). However, the scales of extended dimension such as mobile self-efficacy (MSE) are derived from Nikou and Economides (2017), and Bandura (1986). The items of newly added construct, for instance, perceived enjoyment (PRE), are taken from Law and Fong (2020), and Persada et al. (2019). The scales of social isolation (SIS) are derived from previous studies such as Wilder-Smith and Freedman (2020), De Jong Grieveld et al. (2016), and Iyer et al. (2020). Finally, the items of fear of COVID-19 (FOC) have been extracted from Pakpour and Griffiths (2020), Raza et al. (2021), and Ahmed et al. (2020). 


\subsection{Sampling strategy and data collection method}

The data was gathered from the university students via online and social media mode, for instance, LinkedIn, personal email, Google Docs, and Facebook from Pakistan, India, South Korea, Bangladesh, and Malaysia. The researchers used a purposive sampling strategy for a better representative sample; additionally, this study also employed a quota for every country to a better geographic representation of different Asian countries. The authors selected undergraduate and postgraduate students that are enrolled in different faculties of undertaken countries' universities. The authors have taken 1875 responses in which 464 responses were taken from India, 459 responses were taken from Pakistan, and 367 responses from Bangladesh. However, 287 responses were extracted from South Korea, and 298 responses were taken from Malaysia. The respondents belong to undergraduate, graduate, postgraduate studies.

\subsection{Estimation techniques and software}

The data was analyzed using PLS-SEM through Smart-PLS software version 3.2.3 (Hou et al., 2020). In PLS-SEM, researchers used factor loading, composite reliability, Cronbach's Alpha, average variance extracted, and construct validity. Additionally, authors examined two hypothesized models: structural and measurement models through Smart-PLS (Law \& Fong, 2020). Thus, in the first step, authors examined the measurement model using factor loading, Cronbach's Alpha, composite reliability, and convergent and discriminant validities. In the subsequent step, researchers evaluated the structural model by assessing $\mathrm{R}^{2}$ and path coefficient analyses. The structure model is further validated through path co-efficient analysis via direct hypotheses relationship and mediating relationship. For this purpose, authors again used the PLS-SEM by employing the software of Smart-PLS (Alharbi \& Sohaib, 2021). Finally, researchers examined and measured the moderation effect between exogenous and endogenous variables. For this purpose, researchers employed conditional process analysis (model 1) and also drew the conditional moderating effect via graphs.

\subsection{Respondent's demography}

The authors have collected 1875 responses from Pakistan, India, South Korea, Malaysia, and Bangladesh. The authors have floated questionnaire through social media and another online medium. The demography of respondents demonstrated that researchers had taken $897(47.84 \%)$ responses of males and $978(52.16 \%)$ female responses. The authors gathered 1654(88.21\%) responses from the unmarried respondents and 221(11.79\%) responses from the married respondents. The age bracket of 16-20 years was $671(35.79 \%)$, the age bracket of 21-25 years were $455(24.27 \%)$, the age bracket of $26-30$ years were $388(20.69 \%)$, and the age interval of 31-30 years were 256(13.65\%). However, the rest of the respondents, 105(5.60\%), belonged to more than 35 years of age. Finally, researchers took 965(51.47\%) respondents who belong to undergraduate studies, 645(34.40\%) respondents who belong to graduate studies. However, 265(14.13\%) respondents belong to postgraduate studies. The postgraduate studies include Ph.D. studies. 


\section{Findings and data analyses}

\subsection{Measurement model and descriptive analyses}

The authors have evaluated the normality of the data through Kurtosis, standard deviation, and skewness since the values of standard deviation and skewness are $> \pm 1.5$, and Kurtosis $> \pm 3$. Thus, the data follows the normality pattern (Ahmed et al., 2019). The findings of Table 1 evaluated the measurement model, which demonstrated that the factor loadings are $>0.70$, rho_A $>0.70, \mathrm{CA}>0.70$, composite reliability $>0.70$, and according to Fornell and Larcker (1981), AVE $>0.50$ for individual factors.

Table 1. Measurement model and descriptive statistics

\begin{tabular}{|c|c|c|c|c|c|c|c|c|c|c|}
\hline Constructs & Items & FL & $\mathrm{CA}$ & rho_A & $\mathrm{CR}$ & AVE & $\begin{array}{c}\mathrm{R} \\
\text { Square }\end{array}$ & $\mathrm{SD}$ & SKE & KUR \\
\hline \multirow{4}{*}{$\begin{array}{l}\text { Behavioral } \\
\text { Intention }\end{array}$} & BI1 & 0.697 & \multirow{4}{*}{0.757} & \multirow{4}{*}{0.765} & \multirow{4}{*}{0.846} & \multirow{4}{*}{0.580} & \multirow{4}{*}{0.885} & \multirow{4}{*}{1.090} & \multirow{4}{*}{-0.862} & \multirow{4}{*}{0.184} \\
\hline & BI2 & 0.807 & & & & & & & & \\
\hline & $\mathrm{BI} 3$ & 0.809 & & & & & & & & \\
\hline & BI4 & 0.727 & & & & & & & & \\
\hline \multirow{4}{*}{$\begin{array}{l}\text { Performance } \\
\text { Expectancy }\end{array}$} & PE1 & 0.838 & \multirow{4}{*}{0.81} & \multirow{4}{*}{0.817} & \multirow{4}{*}{0.876} & \multirow{4}{*}{0.639} & & \multirow{4}{*}{1.106} & \multirow{4}{*}{-0.982} & \multirow{4}{*}{0.356} \\
\hline & PE2 & 0.718 & & & & & & & & \\
\hline & PE3 & 0.778 & & & & & & & & \\
\hline & PE4 & 0.857 & & & & & & & & \\
\hline \multirow{4}{*}{$\begin{array}{l}\text { Effort } \\
\text { Expectancy }\end{array}$} & EE1 & 0.853 & \multirow{4}{*}{0.849} & \multirow{4}{*}{0.853} & \multirow{4}{*}{0.898} & \multirow{4}{*}{0.689} & & \multirow{4}{*}{0.977} & \multirow{4}{*}{-1.039} & \multirow{4}{*}{1.379} \\
\hline & EE2 & 0.812 & & & & & & & & \\
\hline & EE3 & 0.855 & & & & & & & & \\
\hline & $\mathrm{EE} 4$ & 0.798 & & & & & & & & \\
\hline \multirow{4}{*}{$\begin{array}{l}\text { Social } \\
\text { Influence }\end{array}$} & SI1 & 0.862 & \multirow{4}{*}{0.829} & \multirow{4}{*}{0.831} & \multirow{4}{*}{0.887} & \multirow{4}{*}{0.665} & & & & \\
\hline & SI2 & 0.800 & & & & & & 1006 & 1023 & 1110 \\
\hline & SI3 & 0.704 & & & & & & 1.000 & $-1.02 \mathrm{~J}$ & 1.107 \\
\hline & SI4 & 0.883 & & & & & & & & \\
\hline & FC1 & 0.904 & & & & & & & & \\
\hline Facilitating & FC2 & 0.780 & 0042 & 0057 & 004 & 0601 & & 1076 & $0 \circ 0$ & 0266 \\
\hline Conditions & FC3 & 0.883 & 0.842 & 0.857 & 0.894 & 0.681 & & $1.0 / 6$ & -0.89 & 0.266 \\
\hline & FC4 & 0.721 & & & & & & & & \\
\hline & MSE1 & 0.838 & & & & & & & & \\
\hline $\begin{array}{l}\text { Mobile Self } \\
\text { Efficacy }\end{array}$ & MSE2 & 0.820 & 0.675 & 0.713 & 0.818 & 0.602 & & 1.094 & -1.011 & 0.441 \\
\hline & MSE3 & 0.657 & & & & & & & & \\
\hline & PRE1 & 0.775 & & & & & & & & \\
\hline 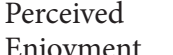 & PRE2 & 0.917 & 0.843 & 0.841 & 0.906 & 0.764 & & 1.051 & -0.966 & 0.603 \\
\hline & PRE3 & 0.923 & & & & & & & & \\
\hline
\end{tabular}


End of Table 1

\begin{tabular}{|c|c|c|c|c|c|c|c|c|c|c|}
\hline Constructs & Items & $\mathrm{FL}$ & CA & rho_A & CR & AVE & $\begin{array}{c}\mathrm{R} \\
\text { Square }\end{array}$ & SD & SKE & KUR \\
\hline \multirow{3}{*}{$\begin{array}{l}\text { Fear of } \\
\text { COVID-19 }\end{array}$} & FOC1 & 0.714 & \multirow{3}{*}{0.791} & \multirow{3}{*}{0.847} & \multirow{3}{*}{0.876} & \multirow{3}{*}{0.703} & & \multirow{3}{*}{1.061} & \multirow{3}{*}{-0.964} & \multirow{3}{*}{0.52} \\
\hline & FOC2 & 0.903 & & & & & & & & \\
\hline & FOC3 & 0.886 & & & & & & & & \\
\hline \multirow{6}{*}{$\begin{array}{l}\text { Social } \\
\text { Isolation }\end{array}$} & SIS1 & 0.718 & \multirow{6}{*}{0.854} & \multirow{6}{*}{0.89} & \multirow{6}{*}{0.887} & \multirow{6}{*}{0.569} & \multirow{6}{*}{0.378} & \multirow{6}{*}{1.072} & \multirow{6}{*}{-0.823} & \multirow{6}{*}{0.255} \\
\hline & SIS2 & 0.717 & & & & & & & & \\
\hline & SIS3 & 0.720 & & & & & & & & \\
\hline & SIS4 & 0.713 & & & & & & & & \\
\hline & SIS5 & 0.805 & & & & & & & & \\
\hline & SIS6 & 0.839 & & & & & & & & \\
\hline \multirow{5}{*}{$\begin{array}{l}\text { Use } \\
\text { Behavior of } \\
\text { LMS }\end{array}$} & UBL1 & 0.952 & \multirow{5}{*}{0.934} & \multirow{5}{*}{0.944} & \multirow{5}{*}{0.951} & \multirow{5}{*}{0.796} & \multirow{5}{*}{0.890} & \multirow{5}{*}{1.082} & \multirow{5}{*}{-0.924} & \multirow{5}{*}{0.309} \\
\hline & UBL2 & 0.839 & & & & & & & & \\
\hline & UBL3 & 0.755 & & & & & & & & \\
\hline & UBL4 & 0.950 & & & & & & & & \\
\hline & UBL5 & 0.946 & & & & & & & & \\
\hline
\end{tabular}

Hence, the convergent validity and reliability of individual scales and constructs have been met. Similarly, this study has evaluated the discriminant validities as depicted in Table 2 that the square roots of AVE values are higher (in diagonal readings) than the correlation of constructs.

Table 2. Discriminant validity - Fornell-Larcker criterion

\begin{tabular}{|l|c|c|c|c|c|c|c|c|c|c|}
\hline $\begin{array}{c}\text { Cons- } \\
\text { truct }\end{array}$ & BI & EE & FC & FOC & MSE & PE & PRE & SI & SIS & UBL \\
\hline BI & 0.762 & & & & & & & & & \\
\hline EE & 0.671 & 0.830 & & & & & & & & \\
\hline FC & 0.725 & 0.754 & 0.825 & & & & & & & \\
\hline FOC & 0.703 & 0.693 & 0.785 & 0.839 & & & & & & \\
\hline MSE & 0.650 & 0.756 & 0.797 & 0.760 & 0.776 & & & & & \\
\hline PE & 0.717 & 0.705 & 0.781 & 0.725 & 0.740 & 0.800 & & & & \\
\hline PRE & 0.588 & 0.567 & 0.648 & 0.626 & 0.668 & 0.613 & 0.874 & & & \\
\hline SI & 0.693 & 0.746 & 0.814 & 0.728 & 0.753 & 0.702 & 0.623 & 0.815 & & \\
\hline SIS & 0.614 & 0.541 & 0.699 & 0.836 & 0.763 & 0.583 & 0.681 & 0.632 & 0.754 & \\
\hline UBL & 0.579 & 0.551 & 0.722 & 0.826 & 0.641 & 0.602 & 0.587 & 0.616 & 0.752 & 0.892 \\
\hline
\end{tabular}

Thus, the criterion of discriminant validities of constructs has been achieved. The outcomes of Table 3 exhibited that the Heterotrait-Monotrait (HTMT) ratio of correlation is less than 0.90 . 
Table 3. Heterotrait-Monotrait Ratio (HTMT)

\begin{tabular}{|l|c|c|c|c|c|c|c|c|c|c|}
\hline $\begin{array}{c}\text { Cons- } \\
\text { truct }\end{array}$ & BI & EE & FC & FOC & MSE & PE & PRE & SI & SIS & UBL \\
\hline BI & & & & & & & & & & \\
\hline EE & 0.881 & & & & & & & & & \\
\hline FC & 0.809 & 0.868 & & & & & & & & \\
\hline FOC & 0.849 & 0.895 & 0.815 & & & & & & & \\
\hline MSE & 0.735 & 0.829 & 0.832 & 0.864 & & & & & & \\
\hline PE & 0.870 & 0.894 & 0.853 & 0.857 & 0.873 & & & & & \\
\hline PRE & 0.716 & 0.654 & 0.759 & 0.782 & 0.869 & 0.726 & & & & \\
\hline SI & 0.723 & 0.701 & 0.881 & 0.832 & 0.828 & 0.802 & 0.726 & & & \\
\hline SIS & 0.737 & 0.605 & 0.802 & 0.829 & 0.856 & 0.668 & 0.794 & 0.721 & & \\
\hline UBL & 0.680 & 0.612 & 0.849 & 0.836 & 0.802 & 0.688 & 0.655 & 0.695 & 0.870 & \\
\hline
\end{tabular}

Thus, finally, the measurement model conditions have been achieved. Hence, the considered hypothesized measurement model is valid for assessing UTAUT dimensions and behavioral intentions and use behavior of LMS.

\subsection{Structural model}

The second phase is to evaluate the structural model by assessing $\mathrm{R}^{2}$ and path coefficient analyses. Figure 1 demonstrated $\mathrm{R}^{2}$ and T-values' values, which decide the significance between independent and dependent variables. Moreover, this is one of the most important criteria for the validation of structural model.

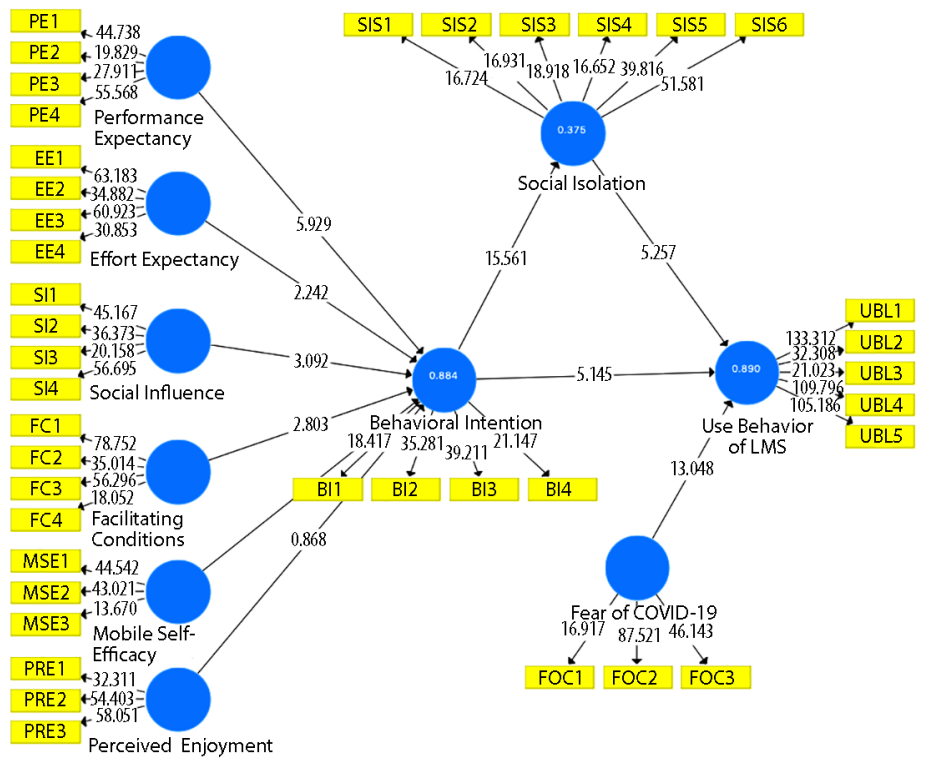

Figure 1. Smart-PLS - path analyses with R-square values (extended UTAUT model) 
Findings of Table 1 and Figure 1 demonstrated the $\mathrm{R}^{2}$, also known as a coefficient of determination, and goodness of fit measure. The reading of $\mathrm{R}^{2}$ showed the collective value of variance in \% that explains the change of dependent variable due to independent variable. Thus, Figure 1 showed that the R-squared of behavioral intention is 0.884 that demonstrates that a total change of $88.4 \%$ of $\mathrm{BI}$ is experienced due to the extended dimensions of the UTAUT model. Similarly, $\mathrm{R}^{2}$ of social Isolation (SIS) is 0.375 , demonstrating that a $37.5 \%$ chance of SIS is experienced due to the BI. Finally, $\mathrm{R}^{2}$ of user behavior of LMS (UBL) is 0.890 shows that a total change of $89.0 \%$ of UBL is experienced due to BI and SIS.

\subsection{Stone-Geisser $\left(Q^{2}\right)$ and $S R M R$ indicator}

Finally, Table 4 exhibited the outcomes of Stone-Geisser or Q2. The findings of Table 4 examined and validated the predictive relevance of the individual endogenous model and its factors. Additionally, the SRMR indicator's outcomes demonstrated the saturated model's value 0.764 \& estimated model value 0.103 , which further validated the structural model's goodness of fit.

Table 4. Stone-Geisser $\left(\mathrm{Q}^{2}\right)$

\begin{tabular}{|l|c|}
\hline \multicolumn{1}{|c|}{ Constructs } & Q2 $=1-$ SSE / SSO \\
\hline BI & 0.4567 \\
\hline PE & \\
\hline EE & \\
\hline SI & \\
\hline FC & \\
\hline MSE & \\
\hline PRE & \\
\hline SIS & 0.2521 \\
\hline FOC & \\
\hline UBL & 0.5432 \\
\hline
\end{tabular}

Moreover, Table 5 and Table 6 showed the values of standard regression weights (path coefficients) and p-values of direct and mediating relationships that depicted the hypothesized structural model's validity.

\subsection{Postulated direct association}

The findings of Table 5 demonstrated the direct hypothesized association between regressors and dependent factors. The outcomes of Table 5 stated that the direct hypotheses $\mathrm{H} 1$ to $\mathrm{H} 5$ and $\mathrm{H} 7$ are reinforced because individual T-values are greater than \pm 1.96 , and corresponding probabilities are less than 0.05 except H6. Hence, it is conclusively established that dimensions of extended UTAUT model such as PE, EE, SI, FC, and MSE significantly impact behavioral intention (BI). Moreover, behavioral intention has a significant influence on LMS user behavior. However, PRE does not exert a cogent influence on BI. The individual 
influence of dimensions demonstrated that performance expectancy showed the maximum influence of 0.538 on BI. Then, trailing by mobile self-efficacy, it has an effect of 0.285 on behavioral intention.

Table 5. Postulated direct association

\begin{tabular}{|c|c|c|c|c|c|c|}
\hline \multirow{2}{*}{$\begin{array}{l}\text { Direct Path } \\
\text { Hypotheses }\end{array}$} & \multirow{2}{*}{$\begin{array}{c}\text { Standardized } \\
\text { Regression } \\
\text { Weights }\end{array}$} & \multirow{2}{*}{ T-Statistics } & \multirow{2}{*}{ P-Values } & \multicolumn{2}{|c|}{$\begin{array}{c}\text { Confidence } \\
\text { Interval }\end{array}$} & \multirow{2}{*}{ Decision } \\
\hline & & & & $2.5 \%$ & $97.5 \%$ & \\
\hline $\mathrm{H} 1: \mathrm{PE}->\mathrm{BI}$ & 0.538 & 5.888 & $0.000^{\star *}$ & 0.376 & 0.737 & Supported \\
\hline H2: EE -> BI & 0.125 & 2.173 & $0.030^{*}$ & 0.013 & 0.240 & Supported \\
\hline H3: SI -> BI & 0.312 & 3.127 & $0.002^{\star *}$ & 0.094 & 0.484 & Supported \\
\hline $\mathrm{H} 4: \mathrm{FC}->\mathrm{BI}$ & 0.275 & 2.884 & $0.004^{\star *}$ & 0.452 & 0.087 & Supported \\
\hline H5: MSE -> BI & 0.285 & 3.273 & $0.001^{\star *}$ & 0.113 & 0.454 & Supported \\
\hline H6: PRE -> BI & -0.020 & 0.877 & 0.380 & -0.067 & 0.024 & Not Supported \\
\hline H7: BI -> UBL & 0.156 & 5.296 & $0.000^{* *}$ & 0.211 & 0.094 & Supported \\
\hline
\end{tabular}

Note: Null hypotheses rejected at: ${ }^{\star} \mathrm{p}<0.05$ and ${ }^{\star *} \mathrm{p}<0.01$.

\subsection{Mediation analyses}

The extended UTAUT model consisted of social isolation as mediating variable. Thus, the findings of Table 6 exhibited that specific indirect relationship (mediation) of social isolation has a significant impact between PE through BI on UBL. Similarly, social isolation (SIS) has a significant mediation between EE, SI, FC \& MSE through BI on UBL. However, the extended dimension of perceived enjoyment (PRE) does have a significant impact on UBL. Similarly, social isolation has a significant moderating impact on the relationship BI and user behavior of LMS (UBL). Thus, it is finally concluded that hypotheses from H8A to H8G, H8B, H8C, H8D, H8E, H8G are supported except H8F because individual T-values are greater than \pm 1.96 , and corresponding probabilities are less than 0.05 .

Table 6. Mediation evaluation

\begin{tabular}{|c|c|c|c|c|c|c|}
\hline \multirow{2}{*}{$\begin{array}{l}\text { Mediation Path } \\
\text { Hypotheses }\end{array}$} & \multirow{2}{*}{$\begin{array}{l}\text { Path } \\
\text { Coeffi- } \\
\text { cient }\end{array}$} & \multirow{2}{*}{$\begin{array}{l}\text { T-Sta- } \\
\text { tistics }\end{array}$} & \multirow{2}{*}{ P-Values } & \multicolumn{2}{|c|}{ BCCI } & \multirow{2}{*}{ Decision } \\
\hline & & & & $2.5 \%$ & $97.5 \%$ & \\
\hline H8A: PE $->$ BI $->$ SIS $->$ UBL & 0.090 & 4.013 & $0.000^{\star *}$ & 0.054 & 0.143 & Supported \\
\hline H8B: EE -> BI $->$ SIS $->$ UBL & 0.021 & 1.997 & $0.046^{*}$ & 0.004 & 0.047 & Supported \\
\hline H8C: FC $->$ BI $->$ SIS $->$ UBL & 0.046 & 2.596 & $0.010^{*}$ & 0.092 & 0.019 & Supported \\
\hline H8D: SI -> BI -> SIS -> UBL & 0.052 & 2.636 & $0.008^{* *}$ & 0.017 & 0.097 & Supported \\
\hline H8E: MSE $->$ BI $->$ SIS $->$ UBL & 0.048 & 2.822 & $0.005^{\star *}$ & 0.020 & 0.087 & Supported \\
\hline H8F: PRE $->$ BI $->$ SIS $->$ UBL & -0.003 & 0.872 & 0.383 & -0.012 & 0.003 & Not Supported \\
\hline H8G: BI -> SIS -> UBL & 0.167 & 5.142 & $0.000^{\star \star}$ & 0.109 & 0.234 & Supported \\
\hline
\end{tabular}

Note: Null hypotheses rejected at: ${ }^{\star} \mathrm{p}<0.05$ and ${ }^{\star *} \mathrm{p}<0.01$. 


\subsection{Moderation analyses using conditional process modeling}

Finally, the undertaken study has examined the moderation between exogenous variables and endogenous variables. For this purpose, this research employed conditional process modeling (Model 1). The findings of Table 7 exhibited the cogent influence of moderator (FOC) between PE, EE, SI, FC, \& MSE, and behavioral intention (BI). Similarly, FOC has a substantial moderation between BI and user behavior of LMS (UBL). However, FOC does not have any moderation between PRE and BI. Thus, it is concluded that H9A, H9B, H9C, H9D, H9E, and H9G are supported except H9F ( $\mathrm{T}> \pm 1.96$ and $\mathrm{p}<0.05)$.

Table 7. Moderation analysis

\begin{tabular}{|l|l|l|c|c|c|c|c|c|}
\hline $\begin{array}{c}\text { Hypo- } \\
\text { theses }\end{array}$ & $\begin{array}{c}\text { Mode- } \\
\text { rator }\end{array}$ & Moderation & $\begin{array}{c}\text { Coeffi- } \\
\text { cient }\end{array}$ & SE & T & P* & LLCI & ULCI \\
\hline \multicolumn{7}{|c|}{ Moderating Effect of FOC b/w PE and Behavioral Intention (BI.) } \\
\hline H9A: & FOC & PE $\times$ FOC & -0.1059 & 0.0060 & -17.69 & 0.0000 & -0.1176 & -0.0941 \\
\hline Moderating Effect of FOC b/w EE and Behavioral Intention (BI.) \\
\hline H9B: & FOC & EE $\times$ FOC & -0.0341 & 0.0049 & -6.95 & 0.0000 & -0.0438 & -0.0245 \\
\hline \multicolumn{7}{|c|}{ Moderating Effect of FOC b/w SI and Behavioral Intention (BI.) } \\
\hline H9C: & FOC & SI $\times$ FOC & -0.0274 & 0.0054 & -5.04 & 0.0000 & -0.0380 & -0.0167 \\
\hline \multicolumn{7}{|c|}{ Moderating Effect of FOC b/w FC and Behavioral Intention (BI.) } \\
\hline H9D: & FOC & FC $\times$ FOC & 0.0177 & 0.0041 & 4.36 & 0.0000 & 0.0097 & 0.0257 \\
\hline \multicolumn{7}{|c|}{ Moderating Effect of FOC b/w MSE and Behavioral Intention (BI.) } \\
\hline H9E: & FOC & MSE $\times$ FOC & -0.0938 & 0.0056 & -16.69 & 0.0000 & -0.1048 & -0.0828 \\
\hline \multicolumn{7}{|c|}{ Moderating Effect of FOC b/w PRE and Behavioral Intention (BI.) } & \\
\hline H9F: & FOC & PRE $\times$ FOC & -0.0099 & 0.0062 & -1.60 & 0.1090 & -0.0221 & 0.0022 \\
\hline \multicolumn{7}{|c|}{ Moderating Effect of FOC b/w BI and Use behavior of LMS } & \\
\hline H9G: & FOC BI $\times$ FOC & -0.0420 & 0.0050 & -8.36 & 0.0000 & -0.0518 & -0.0321 \\
\hline
\end{tabular}

Note: where " $\mathrm{x}$ " denoted for the multiplicative sign; ${ }^{*}$ Indicates rejection of Null Hypotheses at $\mathrm{p}<0.05$.

\subsection{Conditional graphical display of moderation}

According to Ahmed et al. (2020), the graphical display of moderation is more essential than the calculation; therefore, this research generated the readings of moderating variables (fear of COVID-19), exogenous \& endogenous variables, and plotted Figure 2a to Figure 2g. The findings of Figure 2a demonstrated that the change of every reading of moderating factor (FOC) brings a change in an endogenous variable (UBL), which shows a significance of moderation. The exogenous variables such as effort expectancy, performance expectancy, social influence, facilitating conditions, mobile self-efficacy, and perceived enjoyment kept constant and showed in the Blue lines. However, the moderation of fear of COVID-19 is depicted in Red line, and behavioral intention is demonstrated in the green line. The outcome of Figure 2a confirmed the moderation of FOC between effort expectancy and behavioral intention (BI). 


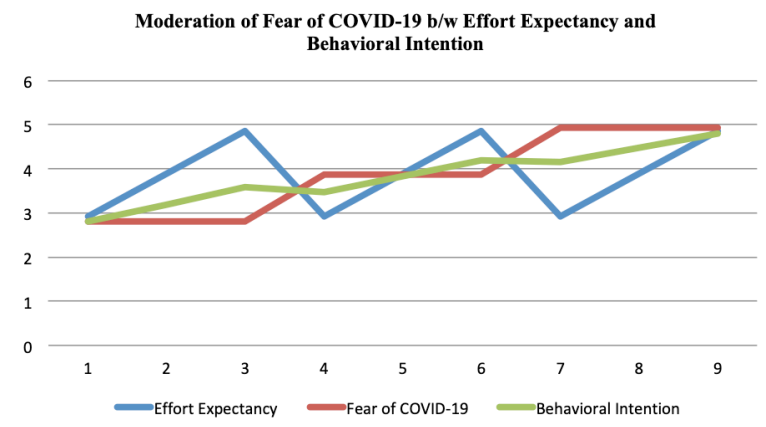

Figure 2a. Moderating influence of FOC between EE and BI

Similarly, the findings of Figure $2 \mathrm{~b}$ demonstrated that the change of every reading of moderating factor (FOC) brings a change in an endogenous variable (BI), which shows a significance of moderation. The outcome of Figure $2 \mathrm{~b}$ confirmed the moderation of FOC between performance expectancy and behavioral intention (BI).

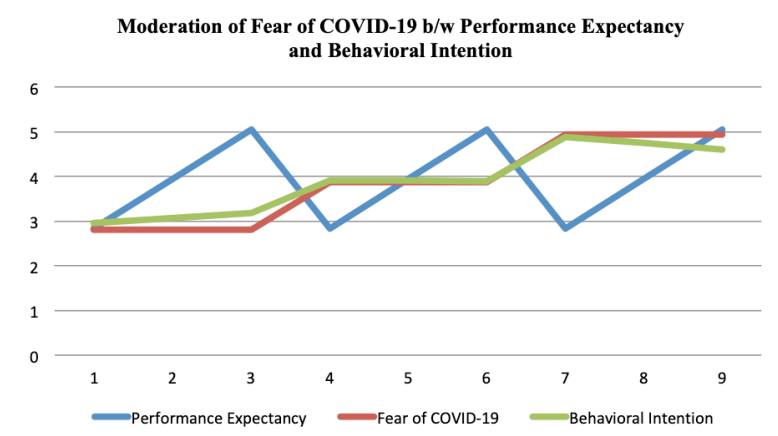

Figure 2b. Moderating influence of FOC between PE and BI

Similarly, the findings of Figure $2 \mathrm{c}$ demonstrated that the change of every reading of moderating factor (FOC) brings a change in an endogenous variable (BI), which shows a significance of moderation. The outcome of Figure $2 \mathrm{c}$ confirmed the moderation of FOC between social influence and behavioral intention (BI).

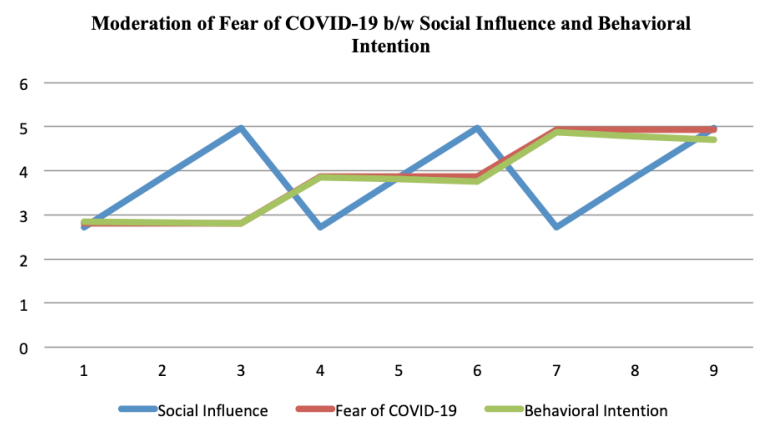

Figure 2c. Moderating influence of FOC between SI and BI

Similarly, the findings of Figure $2 \mathrm{~d}$ demonstrated that the change of every reading of moderating factor (FOC) brings a change in an endogenous variable (BI), which shows a 
significance of moderation. The outcome of Figure $2 \mathrm{~d}$ confirmed the moderation of FOC between facilitating conditions and behavioral intention (BI).

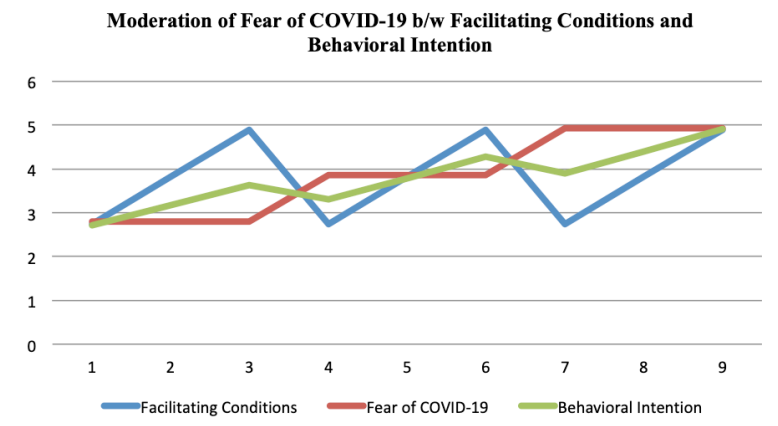

Figure 2d. Moderating influence of FOC between FC and BI

Similarly, the findings of Figure 2e demonstrated that the change of every reading of moderating factor (FOC) brings a change in an endogenous variable (BI), which shows a sign of moderation. The outcome of Figure 2e confirmed the moderation of FOC between mobile self-efficacy and behavioral intention (BI).

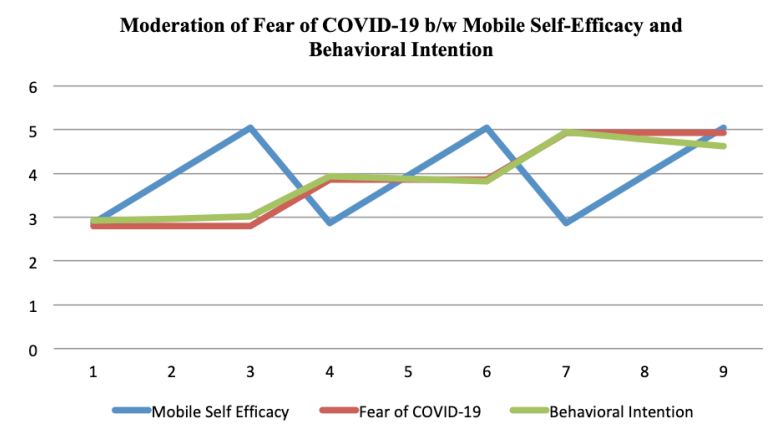

Figure 2e. Moderating influence of FOC between MSE and BI

Similarly, the findings of Figure $2 \mathrm{f}$ demonstrated that the change of every reading of moderating factor (FOC) brings a change in an endogenous variable (BI), which shows a sign of moderation. The outcome of Figure $2 \mathrm{f}$ does not confirm the moderation of FOC between perceived enjoyment and behavioral intention (BI).

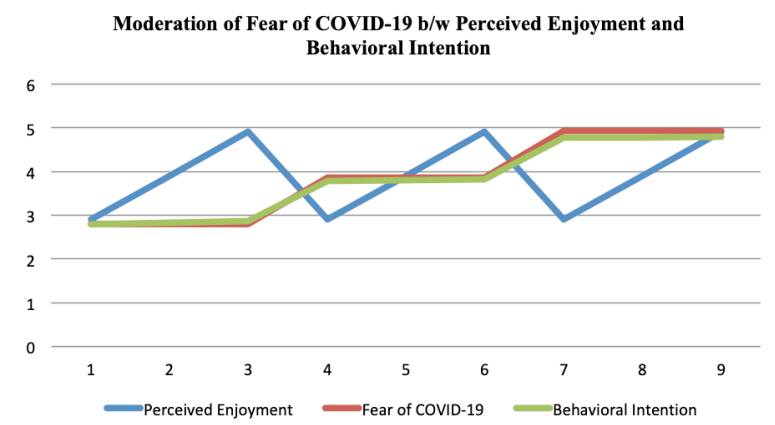

Figure 2f. Moderating influence of FOC between PRE and BI 
Similarly, the findings of Figure $2 \mathrm{~g}$ demonstrated that the change of every reading of moderating factor (FOC) brings a change in an endogenous variable (UBL), which shows a significance of moderation. The outcome of Figure $2 \mathrm{~g}$ confirmed the moderation of FOC between behavioral intention (exogenous variable) and actual use behavior of LMS (UBL).

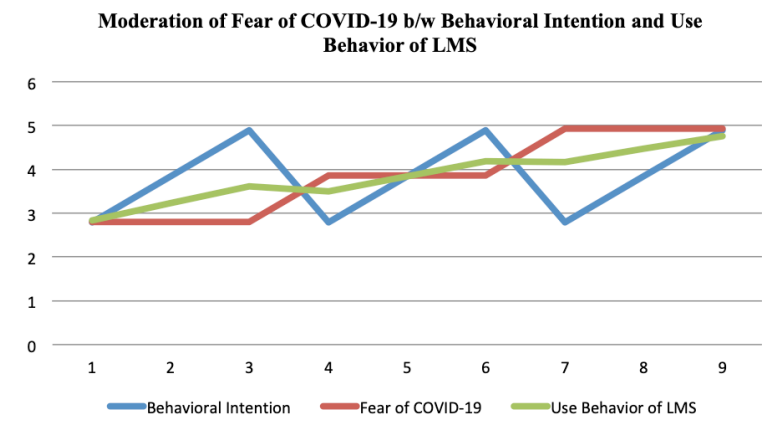

Figure 2g. Moderating influence of FOC between BI and UBL

\section{Discussions}

This research aims to evaluate an extended UTAUT model in which extended two dimensions as predictors, for instance, perceived enjoyment and mobile self-efficacy, and social isolation as a mediator. Moreover, fear of COVID-19 as a moderator in university students taking online classes through LMS during the frightening period of Coronavirus across specific countries such as Pakistan, India, Bangladesh, Malaysia, and South Korea. The discussions are divided into sub-sections such as following:

a) The socio-economic conditions of the South Asian countries, for instance, Pakistan, India, and Bangladesh, are almost similar. However, the socio-economic conditions of Malaysia and South Korea are alike. The online education through LMS is structured and gained acceptance during the COVID-19 period. Previous literature also evaluated the impact of COVID-19 on online learning management system, such as, Almaiah et al. (2020), Raza et al. (2021), and Ahmed et al. (2020). The findings of the undertaken study demonstrated the similar due to the education system, faculty qualification, and students' demographics.

b) Thus, this research examined the impact of independent variables such as social influence, effort expectancy, facilitating conditions, and performance expectancy, Mobile selfefficacy, and perceived enjoyment on behavioral intention (BI), and influence of behavioral intention on the user behavior of LMS (UBL). The findings demonstrated that social influence, effort expectancy, facilitating conditions, and performance expectancy have an affirmative and significant impact on behavioural intention. The outcomes are coherent with the previous research studies such as Aliaño et al. (2019), Chen and Hwang (2019), Kufi et al. (2020), Decman (2015), Hoque and Sorwar (2017), and Khalilzadeh et al. (2017).

c) Similarly, the impact of Mobile self-efficacy demonstrated a cogent and positive influence on behavioral intention, and previous studies also exhibited similar results such as Nikou and Economides (2017), and Bandura (1986). However, the extended factor, perceived enjoyment, does not significantly impact behavioral intention, as, in the educational 
E-system, there is no or substantially less role of perceived enjoyment. Thus, the results are not coherent with the preceding research literature (Lai, 2020; Almisad \& Alsalim, 2020; El-Masri \& Tarhini, 2017).

d) Additionally, this research examined the role of social isolation as a mediating factor in an association between regressors and the actual user behavior of LMS (UBL). The undertaken study's findings suggested that social isolation mediates significantly positively in an association between independent factors, for instance, PE, EE, SI, FC, and MSE, and user behavior of LMS (UBL). The previous literature also demonstrated similar results, for instance, Ahmed et al. (2020), Shahzad et al. (2021), Almaiah et al. (2020), Mertens et al. (2020), De Jong Grieveld et al. (2016), and Wilder-Smith and Freedman (2020). However, social isolation does not mediate between perceived enjoyment (PRE) and the user behavior of LMS (UBL).

e) The undertaken study also examined the moderating impact of fear of COVID-19 between the UTAUT model and UBL dimensions. The findings demonstrated that FOC exerted a cogent effect between extended UTAUT model, for instance, PE, EE, SI, FC, and MSE, and use behavior of LMS (UBL). The previous literature also demonstrated similar results, for instance, Almaiah et al. (2020), Shahzad et al. (2021), Pakpour and Griffiths (2020), Raza et al. (2021), and Ahmed et al. (2020). However, FOC does not moderate between perceived enjoyments (PRE) and user behavior of LMS (UBL).

\section{Conclusions}

The undertaken study examined their influence on behavioral intention and influence of behavioral intention on the user behavior of the Learning Management System. The undertaken study also examined the influence of social isolation as a mediating factor between the exogenous and endogenous variables; finally, this research also incorporated the COVID-19 as a moderating factor and evaluated the moderator's influence between dimensions of the modified UTAUT model and the outcome variable. The findings demonstrated that social influence; effort expectancy, facilitating conditions, and performance expectancy have a significant and affirmative impact on the behavioral intention and influence of behavioral intention on LMS user behavior (UBL). However, the extended factor, perceived enjoyment, does not significantly impact behavioral intention, as, in the educational E-system, there is no or substantially less role of perceived enjoyment. The undertaken study's findings suggested that social isolation mediates significantly \& positively in an association between independent factors, for instance, PE, EE, SI, FC, and MSE, and user behavior of LMS (UBL). However, social isolation does not mediate between perceived enjoyment (PRE) and the user behavior of LMS. The findings further demonstrated that FOC exerted a cogent effect between extended UTUAUT model, for instance, PE, EE, SI, FC, and MSE, and user behavior of LMS (UBL). However, FOC does not moderate between perceived enjoyment (PRE) and the user behavior of LMS. Similarly, the impact of Mobile self-efficacy demonstrated a cogent and positive influence on behavioral intention. The conclusions of the undertaken study established that the modified UTAUT model is a valuable instrument to examine the influence of behavioral intention on the user behavior of LMS (UBL). Finally, the conclusions of this research demonstrated that social influence; effort expectancy, facilitating conditions, and 
performance expectancy have significant impact on the behavioral intention. The findings of this research demonstrated significant theoretical and practical implications; for instance, the new modified conceptual model is a significant addition to the current body of knowledge, which will enhance the dimensions of the UTAUT model. This research provides the real foils to future researchers to replicate this modified model in perspectives of other regional and developed countries' online education systems and evaluate the effectiveness of the learning management system. This research's findings provide several practical implications; first of all, IT departments of universities should take appropriate action to improve their current LMS for more attendance and effectiveness. The teachers should be more vigilant and prepared as compared to the conventional education system. The parents of students should also monitor the universities' LMS and their effectiveness and gauge the students' learning capacity through LMS. Lastly, the universities should also concentrate on LMS and incorporate the latest and exciting modes of education imparting methods to enhance LMS efficiency. This research study has taken only a few Asian countries; thus, future studies should take more emerging and developing economies to evaluate the impact of LMS in a situation like COVID-19. Thus, the outcomes could be more generalizable, and can predict the usefulness of LMS during COVID-19. The number of respondents is limited for the undertaken study; future studies may take a greater sample size for more robust results. This study has employed multivariate SEM-based modeling for the undertaken study that could not examine the cause and effect between the variables. Therefore, it is recommended to future researchers to incorporate better modeling, which also evaluates the cause and effect between the variables. Finally, this research has taken only two new dimensions as independent and social isolation as a mediating and COVID-19 as moderating variables. Future research studies may take some more relevant mediating and moderating variables for better understanding and robustness.

\section{References}

Ahmed, R. R., Hussain, S., Pahi, M. H., Usas, A., \& Jasinskas, E. (2019). Social media handling and extended technology acceptance model (ETAM): Evidence from SEM-based Multivariate Approach. Transformations in Business \& Economics, 18(3(48)), 246-271. https://www.academia. edu/41582543/Social_Media_Handling_and_Extended_Technology_Acceptance_Model_ETAM_ Evidence_from_Sem-Based_Multivariate_Approach

Ahmed, R. R., Štreimikiene, D., Rolle, J. A., \& Due, P. A. (2020). The COVID-19 Pandemic and the antecedents for the Impulse buying behavior of US Citizens. Journal of Competitiveness, 12(3), 5-27. https://doi.org/10.7441/joc.2020.03.01

Ain, N., Kaur, K., \& Waheed, M. (2016). The influence of learning value on learning management system use: An extension of UTAUT2. Information Development, 32(5), 1306-1321. https://doi.org/10.1177/0266666915597546

Alharbi, A., \& Sohaib, O. (2021). Technology readiness and cryptocurrency adoption: PLS-SEM and deep learning neural network analysis. IEEE Access, 9, 21388-21394.

https://doi.org/10.1109/ACCESS.2021.3055785

Alhramelah, A., \& Al-Shahrani, H. (2020). Saudi graduate student acceptance of blended learning courses based upon the unified theory of acceptance and use of technology. Australian Educational Computing, 35(1), 1-22. https://www.researchgate.net/publication/344711887_Saudi_graduate_student_acceptance_of_blended_learning_courses_based_upon_the_unified_theory_of_acceptance_ and_use_of_technology 
Aliaño, Á. M., Hueros, A. M. D., Franco, M. D. G., \& Aguaded, I. (2019). Mobile learning in university contexts based on the unified theory of acceptance and use of technology (UTAUT). Journal of New Approaches in Educational Research, 8(1), 7-17. https://doi.org/10.7821/naer.2019.1.317

Almaiah, M. A., Al-Khasawneh, A., \& Althunibat, A. (2020). Exploring the critical challenges and factors influencing the E-learning system usage during COVID-19 pandemic. Education and Information Technologies, 25, 5261-5280. https://doi.org/10.1007/s10639-020-10219-y

Almisad, B., \& Alsalim, M. (2020). Kuwaiti female university students' acceptance of the integration of smartphones in their learning: An investigation guided by a modified version of the unified theory of acceptance and use of technology (UTAUT). International Journal of Technology Enhanced Learning, 12(1), 1-19. https://doi.org/10.1504/IJTEL.2020.103812

Alshurideh, M., Al Kurdi, B., Salloum, S. A., Arpaci, I., \& Al-Emran, M. (2020). Predicting the actual use of m-learning systems: A comparative approach using PLS-SEM and machine learning algorithms. Interactive Learning Environments, 1-15. https://doi.org/10.1080/10494820.2020.1826982

Bandura, A. (1986). Social foundations of thought and action: A social cognitive theory. Prentice-Hall. https://psycnet.apa.org/record/1985-98423-000

Chen, P.-Y., \& Hwang, G.-J. (2019). An empirical examination of the effect of self-regulation and the Unified Theory of Acceptance and Use of Technology (UTAUT) factors on the online learning behavioural intention of college students. Asia Pacific Journal of Education, 39(1), 79-95. https://doi.org/10.1080/02188791.2019.1575184

Davis, F. D. (1989). Perceived usefulness, perceived ease of use, and user acceptance of information technology. MIS Quarterly, 13(3), 319-340. https://doi.org/10.2307/249008

Davis, F. D., Bagozzi, RP, \& Warshaw, P. R. (1989). User acceptance of computer technology: A comparison of two theoretical models. Management Science, 35(8), 982-1003. https://doi.org/10.1287/mnsc.35.8.982

De Jong Gierveld, J., Van Tilburg, T., \& Dykstra, P. (2016). Loneliness and social isolation. In A. Vangelisti \& D. Perlman (Eds.), The Cambridge handbook of personal relationships (pp. 1-30). Cambridge University Press. http://hdl.handle.net/1765/93235

Decman, M. (2015). Modeling the acceptance of e-learning in mandatory environments of higher education: The influence of previous education and gender. Computers in Human Behavior, 49, 272-281. https://doi.org/10.1016/j.chb.2015.03.022

El-Masri, M., \& Tarhini, A. (2017). Factors affecting the adoption of e-learning systems in Qatar and USA: Extending the Unified Theory of Acceptance and Use of Technology 2 (UTAUT2). Educational Technology Research and Development, 65, 743-763. https://doi.org/10.1007/s11423-016-9508-8

Fishbein, M., \& Ajzen, I. (1975). Belief, attitude, intention, and behavior: An introduction to theory and research. Addison-Wesley, Reading, MA. https://www.researchgate.net/publication/233897090_Belief_attitude_intention_and_behaviour_An_introduction_to_theory_and_research

Fornell, C., \& Larker, D. (1981). Structural equation modeling and regression: Guidelines for research practice. Journal of Marketing Research, 18(1), 39-50. https://doi.org/10.1177/002224378101800104

Garrett, L. (2020). COVID-19: The medium is the message. Lancet, 395(10228), 942-943. https://doi.org/10.1016/S0140-6736(20)30600-0

Hoque, R., \& Sorwar, G. (2017). Understanding factors influencing the adoption of mHealth by the elderly: An extension of the UTAUT model. International Journal of Medical Informatics, 101, 75-84. https://doi.org/10.1016/j.ijmedinf.2017.02.002

Hou, H.-Y., Lo, Y.-L., \& Lee, C.-F. (2020). Predicting network behavior model of e-learning partner program in PLS-SEM. Applied Sciences, 10(13), 4656. https://doi.org/10.3390/app10134656

Iqbal, S. (2011). Learning management systems (LMS): Inside matters. Information Management and Business Review, 3(4), 206-216. https://doi.org/10.22610/imbr.v3i4.935 
Iyer, G. R., Blut, M., Xiao, S. H., \& Grewal, D. (2020). Impulse buying: a meta-analytic review. Journal of the Academy of Marketing Science, 48, 384-404. https://doi.org/10.1007/s11747-019-00670-w

Khalilzadeh, J., Ozturk, A. B., \& Bilgihan, A. (2017). Security-related factors in extended UTAUT model for NFC based mobile payment in the restaurant industry. Computers in Human Behavior, 70, 460-474. https://doi.org/10.1016/j.chb.2017.01.001

Khechine, H., Lakhal, N., \& Ndjambou, P. (2016). A meta-analysis of the UTAUT model: Eleven years later. Canadian Journal of Administrative Sciences, 33(2), 138-152. https://doi.org/10.1002/cjas.1381

Kufi, E. F., Negassa, T., Melaku, R., \& Mergo, R. (2020). Impact of corona pandemic on educational undertakings and possible breakthrough mechanisms. BizEcons Quarterly, 11, 3-14. https://ideas.repec.org/a/ris/buecqu/0022.html

Lai, H.-J. (2020). Investigating older adults' decisions to use mobile devices for learning, based on the unified theory of acceptance and use of technology. Interactive Learning Environments, 28(7), 890-901. https://doi.org/10.1080/10494820.2018.1546748

Law, L., \& Fong, N. (2020). Applying partial least squares structural equation modeling (PLS-SEM) in an investigation of undergraduate students' learning transfer of academic English. Journal of English for Academic Purposes, 46, 100884. https://doi.org/10.1016/j.jeap.2020.100884

Limaye, R. J., Sauer, M., Ali, J., Bernstein, J., Wahl, B., Barnhill, A., \& Labrique, A. (2020). Building trust while influencing online COVID-19 content in the social media world. Lancet Digital Health, 2(6), e277-e278. https://doi.org/10.1016/S2589-7500(20)30084-4

Lin, C. Y. (2020). Social reaction toward the 2019 novel coronavirus (COVID-19). Social Health and Behavior, 3(1), 1-2. https://doi.org/10.4103/SHB.SHB_11_20

Mattila, M. (2004). Contested decisions: Empirical analysis of voting in the European Union Council of Ministers. European Journal of Political Research, 43(1), 29-50.

https://doi.org/10.1111/j.1475-6765.2004.00144.x

Mertens, G., Gerritsen, L., Duijndam, S., Salemink, E., \& Engelhard, I. M. (2020). Fear of the Coronavirus (COVID-19): Predictors in an online study conducted in March 2020. Journal of Anxiety Disorders, 74, 102258. https://doi.org/10.1016/j.janxdis.2020.102258

Nikou, S. A., \& Economides, A. A. (2017). Mobile-based assessment: investigating the factors that influence behavioral intention to use. Computer \& Education, 109, 56-73. https://doi.org/10.1016/j.compedu.2017.02.005

Pakpour, A. H., \& Griffiths, M. D. (2020). The fear of Covid-19 and its role in preventive behaviors. Journal of Concurrent Disorders, 2(1), 58-63. http://irep.ntu.ac.uk/id/eprint/39561/

Persada, S. F., Miraja, B. A., \& Nadlifatin, R. (2019). Understanding the generation z behavior on D-learning: A Unified Theory of Acceptance and Use of Technology (UTAUT) approach. International Journal of Emerging Technologies in Learning, 14(5), 20-33. https://doi.org/10.3991/ijet.v14i05.9993

Raza, S. A., Qazi, W., Khan, K. A., \& Salam, J. (2021). Social isolation and acceptance of the Learning Management System (LMS) in the time of COVID-19 Pandemic: An expansion of the UTAUT Model. Journal of Educational Computing Research, 59(2), 183-208. https://doi.org/10.1177/0735633120960421

Rogers, E. M. (2003). Diffusion of innovations (5 $5^{\text {th }}$ ed.). Simon and Schuster. https://www.simonandschuster.com/books/Diffusion-of-Innovations-5th-Edition/Everett-M-Rogers/9780743222099

Shahzad, A., Hassan, R., Aremu, A. Y., Hussain, A., \& Lodhi, R. N. (2021). Effects of COVID-19 in Elearning on higher education institution students: The group comparison between male and female. Quality and Quantity, 55, 805-826. https://doi.org/10.1007/s11135-020-01028-Z

Šumak, B., \& Šorgo, A. (2016). The acceptance and use of interactive whiteboards among teachers: Differences in UTAUT determinants between pre- and post-adopters. Computers in Human Behavior, 64, 602-620. https://doi.org/10.1016/j.chb.2016.07.037 
Taylor, S., \& Todd, P. A. (1995). Understanding information technology usage: A test of competing models. Information Systems Research, 6(2), 144-176. https://doi.org/10.1287/isre.6.2.144

Thompson, R. L., Higgins, C. A., \& Howell, J. M. (1991). Personal computing: toward a conceptual model of utilization. MIS Quarterly, 15(1), 125-143. https://doi.org/10.2307/249443

Vallerand, R. J. (1997). Toward a hierarchical model of intrinsic and extrinsic motivation. In M. P. Zanna (Ed.), Advances in experimental social psychology (pp. 271-360). Academic Press. https://doi.org/10.1016/S0065-2601(08)60019-2

Venkatesh, V., \& Davis, F. D. (2000). A theoretical extension of the technology acceptance model: Four longitudinal field studies. Management Science, 46(2), 186-204. https://doi.org/10.1287/mnsc.46.2.186.11926

Venkatesh, V., Morris, M. G., Davis, G. B., \& Davis, F. D. (2003). User acceptance of information technology: Toward a unified view. MIS Quarterly, 27(3), 425-478. https://doi.org/10.2307/30036540

Wilder-Smith, A., \& Freedman, D. O. (2020). Isolation, quarantine, social distancing and community containment: pivotal role for old-style public health measures in the novel coronavirus (2019nCoV) outbreak. Journal of Travel Medicine, 27(2), taaa020. https://doi.org/10.1093/jtm/taaa020

Xian, X. (2019). Empirical investigation of E-learning adoption of university teachers: A PLS-SEM approach. In Communications in computer and information science: Vol. 1048. Technology in education: Pedagogical innovations (pp. 169-178). Springer, Singapore.

https://doi.org/10.1007/978-981-13-9895-7_15 